\title{
Eddy Current Inspection of INCONEL-600 Steam Generator Tubes at the Tube Sheet
}

Prepared by C. J. Morris, G. H. Lyon, T. J. Davis, C. B. Perry

Pacific Northwest Laboratory

Operated by

Battelle Memorial Institute

Prepared for

U.S. Nuclear Regulatory

Commission 


\section{NOTICE}

This report was prepared as an account of work sponsored by an agency of the United States Government. Neither the United States Government nor any agency thereof, or any of their employees, makes any warranty, expressed or implied, or assumes any legal liability or responsibility for any third party's use, or the results of such use, of any information. apparatus product or process disclosed in this report, or represents that its use by such third party would not infringe privately owned rights.

Available from

GPO Sales Program

Division of Technical Information and Document Control

U. S. Nuclear Regulatory Commission Washington, D. C. 20555

and

National Technical Information Service Springfield, Virginia 22161 


\section{Eddy Current Inspection of INCONEL-600 Steam Generator Tubes at the Tube Sheet}

Manuscript Completed: September 1980

Date Published: November 1980

Prepared by

C. J. Morris, G. H. Lyon, T. J. Davis, C. B. Perry

Pacific Northwest Laboratory

Richland, WA 99352

Prepared for Division of Reactor Safety Research Office of Nuclear Regulatory Research U.S. Nuclear Regulatory Commission Washington, D.C. 20555

NRC FIN No. B2097 



\section{ABSTRACT}

The ability of eddy current inspection to detect and size flaws in Inconel 600 steam generator tubing at the tube sheet was studied. Single frequency absolute, single frequency differential, and multifrequency differential eddy current tests were conducted on small, medium, and large volume defects placed into a simulated tube sheet. Position of each defect was varied with respect to the surface of the tube sheet. Results are presented on detectability and sizing of the defects versus measurement method, location of the defect relative to the tube sheet surface, and defect volume. 

This laboratory investigation of flawed steam generator tubing examined three test cases: (1) Case A - flaw is positioned under the tube sheet; (2) Case B - flaw is half under the tube sheet, and (3) Case C - flaw is above tube sheet. Single-frequency differential and absolute eddy current test results are presented for each test case. The results showed that multiple-frequency eddy current testing was clearly able to detect and size medium (elliptical wastage) and large (uniform thinning) wastage flaws that were as small as $20 \%$ of the tube wall thickness (nominal 0.050 inch) in depth for each of three cases studied. Multiplefrequency eddy current results showed that electro-discharge machine (EDM) slots ( 20.20 inch long) that were less than $30 \%$ of the wall thickness in depth were not detected for each test case. EDM slots greater than $30 \%$ of the wall thickness in depth were clearly detected and sized in depth for each test case. 



\section{CONTENTS}

\begin{tabular}{|c|c|c|c|c|c|c|c|c|}
\hline ABST & RACT & · & • & & $\cdot$ & $\cdot$ & - & • \\
\hline SUMM & ARY & . & - & - & - & - & - & s \\
\hline ACKN & OWLEDGEMENT & - & - & . & . & - & • & \\
\hline INTR & DDUCTION & - & . & . & - & . & - & . \\
\hline TUBE & FLAW MATRIX & . & - & . & - & - & - & . \\
\hline TEST & METHOD . & - & - & . & & . & - & 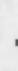 \\
\hline EDDY & CURRENT RESUL & LTS & . & - & - & . & - & . \\
\hline & Flaw Evaluati & ion & . & - & . & - & . & . \\
\hline & Single-Freque & ency & Diff & ntial $T$ & Test $R$ & esults & . & . \\
\hline & Single-Freque & ency & Abso & e Test & Resul & ts & - & . \\
\hline & Multiple-Freq & quencj & & rential & 1 Test & Resul & ts & . \\
\hline
\end{tabular}




\section{FIGURES}

1 EDM Slots, Elliptical Wastage, and Uniform Thinning . . 2

2 Flawed Tube Test Case A, B, and C at the Tube Sheet . . 3

3 Elliptical Wastage Results for SFDECT . . . . . 8

4 Uniform Thinning Wastage Results for SFDECT . . . . 8

5 EDM Slot Results for SFDECT . . . . . . . . $g$

6 Elliptical Wastage Results for SFAECT . . . . . 10

7 Uniform Thinning Wastage for SFAECT . . . . 10

8 Elliptical Wastage Results for MFDECT . . . . . 12

9 Uniform Thinning Wastage Results for MFDECT . . . . 12

10 EDM Slot Results for MFDECT . . . . . . 13 


\section{$\underline{\text { TABLES }}$}

1 Elliptical Wastage Flaw Dimensions . . . . . 4

2 Uniform Thinning Wastage Flaw Dimensions . . . . 4

3 EDM Slot Flaw Dimensions . . . . . . . 5

Single-Frequency Absolute Test Results for a 100\% Stress
Corrosion Crack Specimen $(B-46-4)$. . . 11 



\section{ACKNOWLEDGEMENT}

The authors wish to acknowledge the assistance of R. L. Burr, R. A. Clark, and M. S. Goody in preparing this report for publication. 



\section{INTRODUCTION}

Eddy current inspection of flawed Inconel-600 steam generator tubes was performed under laboratory conditions. Tube specimens with machine induced flaws, typical of reported service flaws, were measured using both single-frequency and multiple-frequency eddy current testing techniques. The object of this test program was to provide initial baseline measurement data that will show current flaw measurement capability for both single-frequency and multiple-frequency eddy current testing techniques about the tube sheet region in steam generators.

\section{TUBE FLAW MATRIX}

A 4 inch long section of carbon steel with a bored center section to accept the steam generator tubing was used to simulate the tube sheet. Inconel-600 tubes, with a diameter of 0.875 inches and wall thickness of 0.05 inches, were used in the program. An annulus of 0.008-0.010 inches existed between the Inconel tube and simulated tube sheet. Figure 1 shows the three types of machined flaws that were tested. Elliptical wastage is considered to be a medium volume wastage flaw, whereas uniform thinning wastage is considered to be a large volume wastage flaw. Electro-discharge machined (EDM) slots are crack type flaws and are small in volume. Because of the unavailability of a $100 \%$ throughwall EDM slot, a stress corrosion crack specimen with a $100 \%$ throughwall crack was substituted in the flaw matrix. Tables 1, 2, and 3 show flaw dimension data for elliptical wastage, uniform thinning wastage and EDM slot tubes.

\section{TEST METHOD}

In order to assess eddy current measurement capability at the tube sheet region, three test cases were considered. Figure 2 shows the three cases of interest with elliptical wastage as an example. Case $A$ shows the flaw under the tube sheet. Case $B$ shows the flaw position one half under the tube sheet. Case $C$ shows the leading edge of the flaw approximately $3 / 16$ to $1 / 4$ inch above the tube sheet. 

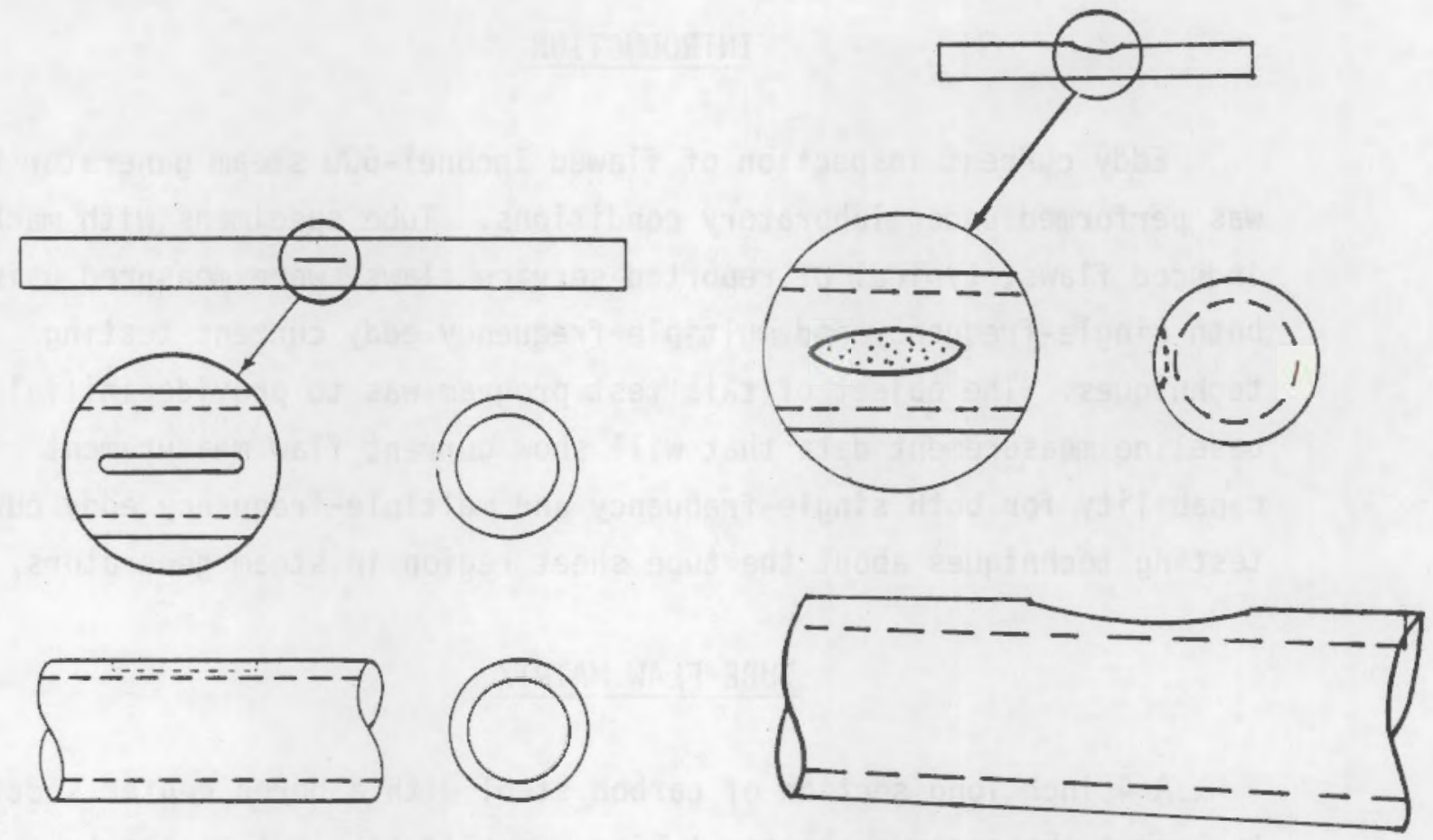

(a) EDM Slot

(b) Elliptical Wastage

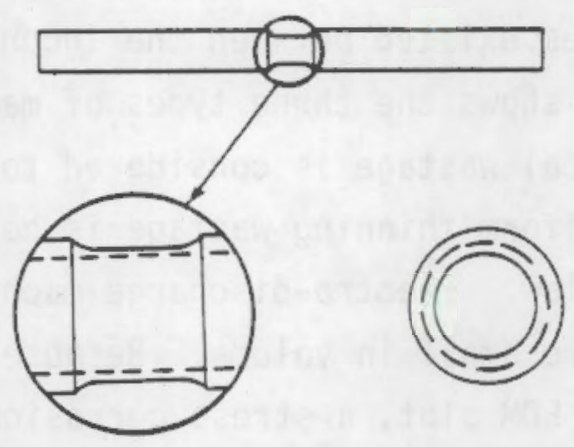

(c) Uniform Thinning

FIGURE 1. EDM Slots, Elliptical Wastage, and Uniform Thinning Wastage Flaw Specimens 


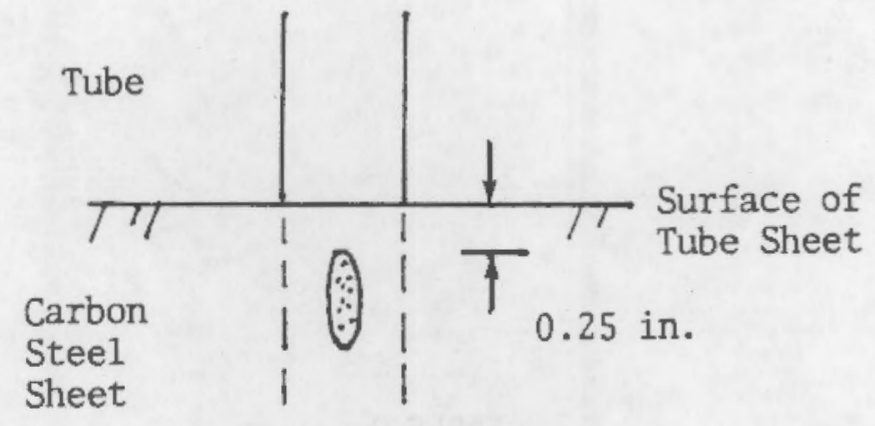

(a) CASE A-- flaw under tube sheet

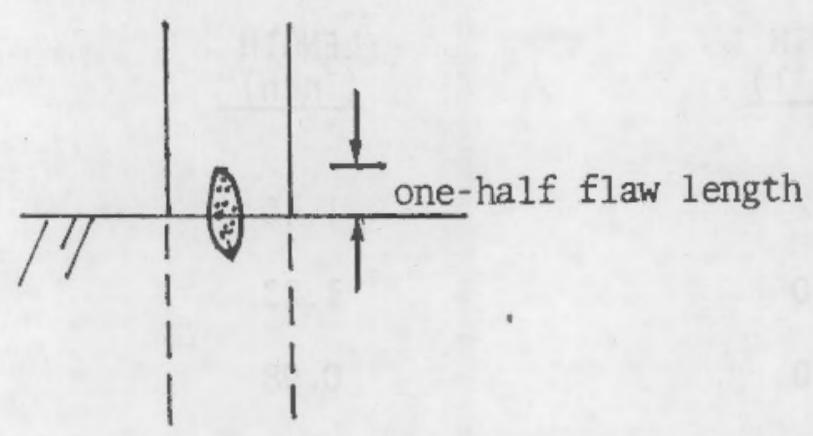

(b) CASE B-- flaw at tube sheet transition

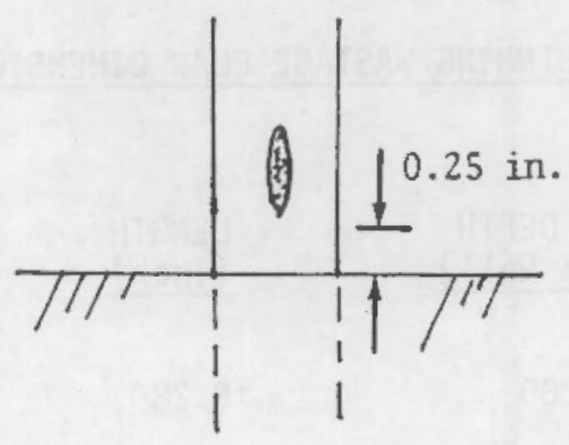

(c) CASE C-- flaw above tube sheet

FIGURE 2. Flawed Tube Test Case A,B, and C at the Tube Sheet 
TABLE 1

\section{ELLIPTICAL WASTAGE FLAW DIMENSIONS}

$\begin{array}{ccc}\begin{array}{c}\text { DEPTH } \\ (\% \text { Wa 1 })\end{array} & \begin{array}{c}\text { LENGTH } \\ \text { (Inch) }\end{array} & \begin{array}{c}\text { WIDTH } \\ \text { (Inch) }\end{array} \\ 80.2 & 1.40 & 0.380 \\ 66.0 & 1.23 & 0.342 \\ 43.0 & 0.98 & 0.280 \\ 22.0 & 0.72 & 0.208\end{array}$

TABLE 2

UNIFORM THINNING WASTAGE FLAW DIMENSIONS

$\begin{array}{cc}\begin{array}{cc}\text { DEPTH } \\ (\% \text { Wa 11) }\end{array} & \begin{array}{l}\text { LENGTH } \\ \text { (Inch })\end{array} \\ 80 & 0.280 \\ 62 & 0.280 \\ 41 & 0.280 \\ 22 & 0.280\end{array}$


TABLE 3

\section{EDM SLOT FLAW DIMENSIONS}

\begin{tabular}{lcccc}
$\begin{array}{c}\text { TUBE } \\
\text { N0. }\end{array}$ & $\begin{array}{c}\text { SLOT } \\
\text { NO. }\end{array}$ & $\begin{array}{c}\text { DEPTH } \\
(\% \text { Wa 1 })\end{array}$ & $\begin{array}{c}\text { LENGTH } \\
\text { (Inch })\end{array}$ & $\begin{array}{c}\text { WIDTH } \\
\text { (Inch })\end{array}$ \\
\cline { 2 - 2 } & D-3 & 20 & 0.195 & 0.0035 \\
PNL-1 & F-2 & 28 & 0.205 & 0.005 \\
PNL-2 & G-2 & 36 & 0.185 & 0.0035 \\
A-21 & H & 50 & 0.250 & 0.010 \\
PNL-2 & H-1 & 63 & 0.190 & 0.011 \\
PNL-2 & I-1 & 71 & 0.190 & 0.005 \\
PNL-2 & J-1 & 80 & 0.180 & 0.007 \\
PNL-2 & M-1 & 92 & 0.210 & 0.016 \\
B-46-4 & SCC & $100(a)$ & 0.720 & 0.0015
\end{tabular}

(a) Single-frequency ECT indicates SCC crack has varying depth from $80 \%$ to $100 \%$ wall. 
The American Society of Mechanical Engineers (ASME) Boiler and Pressure Vessel Code, Appendix IV (referred: ASME Code) has specific calibration and procedure requirements for the single-frequency eddy current testing of steam generator tubes. The calibration and procedure requirements dictated by the ASME Code were followed in this test program. Test results represent measurements taken by a single operator. Multi-scans were conducted to assure repeatability.

Single-frequency differential eddy current testing (SFDECT) is the current as-practiced technique for inspection of steam generator tubing. Single-frequency absolute eddy current testing (SFAECT) has also been employed in the inspection of steam generator tubing (a). Multiplefrequency differential eddy current testing (MFDECT) is now being used on a routine basis for in-service inspection of steam generator tubing. A three frequency eddy current instrument was used in this test program. Frequencies of $200 \mathrm{kHz}, 400 \mathrm{kHz}$, and $1.6 \mathrm{MHz}$ are electronically mixed in order to cancel extraneous tube sheet/support plate signals and probe wobble (noise). The $200 \mathrm{kHz}$ and $400 \mathrm{kHz}$ frequencies are mixed to cancel tube sheet/support plate signals. The $1.6 \mathrm{MHz}$ and $400 \mathrm{kHz}$ frequencies are mixed to cancel probe wobble. The MIZ-12 ${ }^{(b)}$ multiple-frequency eddy current inspection system was used to inspect tubing at Point Beach. This system uses a two frequency mix. It was reported ${ }^{(c)}$ that frequencies of $100 \mathrm{kHz}$ and $400 \mathrm{kHz}$ were used for the Point Beach inspection. It is anticipated that there is little difference in the $100 \mathrm{kHz}$ versus 200 $\mathrm{kHz}$ mix.

\section{EDDY CURRENT RESULTS}

\section{FLAW EVALUATION}

The results of the SFDECT and SFAECT are shown in Figures 3 through 7 and Table 4. The results of the MFDECT are shown in Figures 8, 9, and 10. The single-frequency and multiple-frequency test results were analyzed and evaluated using video and analog signal data. Three distinct flaw evaluation categories were determined from the analysis.

(a) Rochester Gas and Electric Corporation, R. E. Ginnā 490Mwe Plant.

(b) Zetec, Inc., Issaquah, WA.

(c) Mr. J. C. Hagood, Westinghouse Electric Corporation, Pittsburgh, PA. 
The categories were (1) flaw clearly detected and sized in depth, (2) flaw detected only - unable to determine flaw depth, (3) flaw undetected. Further clarification of category (2) is in order and applies specifically to single-frequency data analysis. For the case of small and medium volume flaws located about the tube sheet region (Figure 2, Case B), the dominant effect from the tube sheet signal indication tends to mask flaw signal data. However, flaws of certain depth, length, and width can affect the tube sheet signal indication to the degree that the tube sheet signal is significantly distorted. This then becomes the means whereby skilled eddy current data interpreters would be alerted to the presence of some flaw anomally in this region of interest. Hence, if distorted sheet signals are observed, the interpreter would assume a flaw existed in the region; however, estimating flaw depth from pattern phase or analog data interpretation is difficult, if not impossible. One could make a qualitative estimate of the flaw depth based on known signal response data generated from laboratory samples or actual pulled tubes from service generators. To conclude, the interpreter is alerted to the flaw presence at the tube sheet transition region (Case $B$ ) by the distorted sheet signal.

\section{SINGLE-FREQUENCY DIFFERENTIAL TEST RESULTS}

Figure 3 shows the SFDECT results for elliptical wastage specimens for test Cases A, B, and C. The results show that elliptical wastage flaws with depths of $43 \%$ of the wall thickness (\% wa11) and greater were either detected or clearly detected and sized in each case. An elliptical wastage 17 aw $22 \%$ wall in depth went undetected for test Cases A and B. This flaw was clearly detected and sized in Case C.

Figure 4 shows the SFDECT results for uniform thinning wastage specimens for test Cases $A, B$, and $C$. The results show that uniform thinning wastage is clearly detected and sized in each case.

Figure 5 shows the SFDECT results for EDM slot specimens for test Cases $A, B$, and $C$. The results show that small EDM slots (length approximately 0.20 inch) less than $30 \%$ of the wall in depth went undetected in each case. An EDM slot that was $36 \%$ of the wall in depth was clearly 


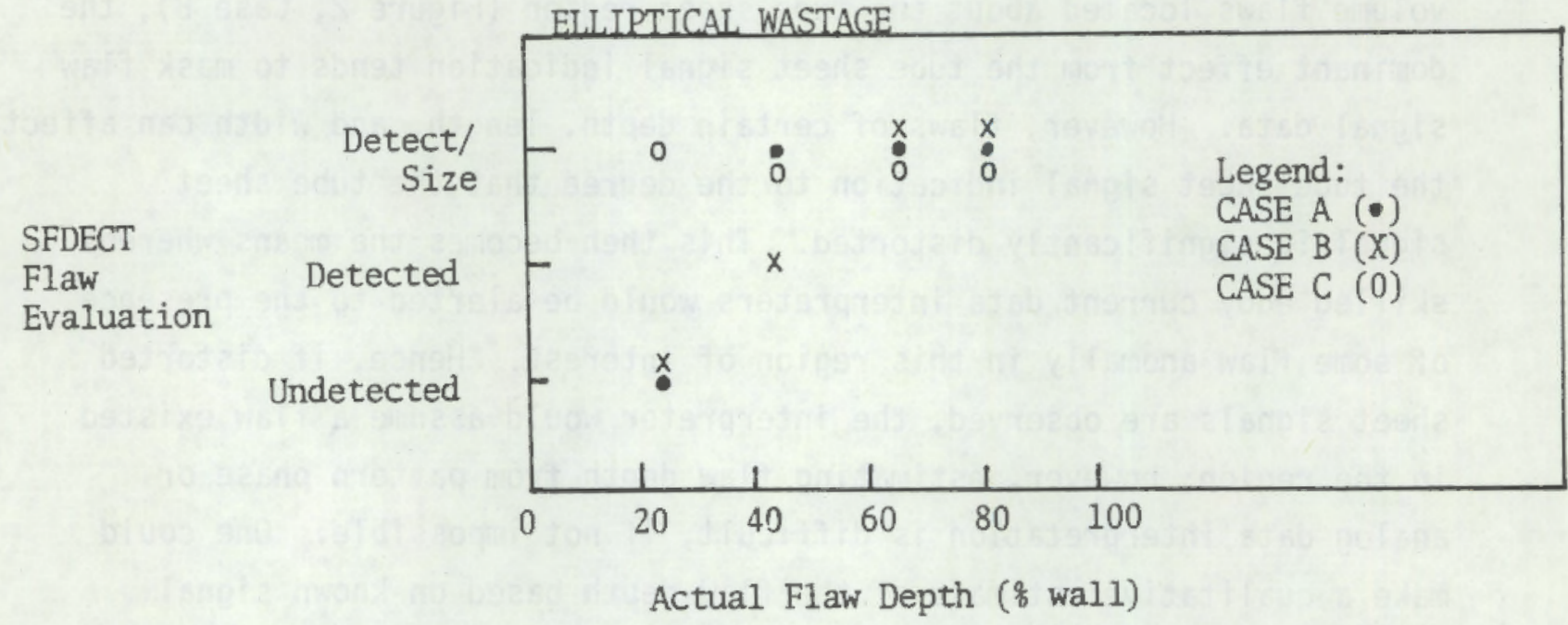

FIGURE 3. Elliptical Wastage Results for SFDECT

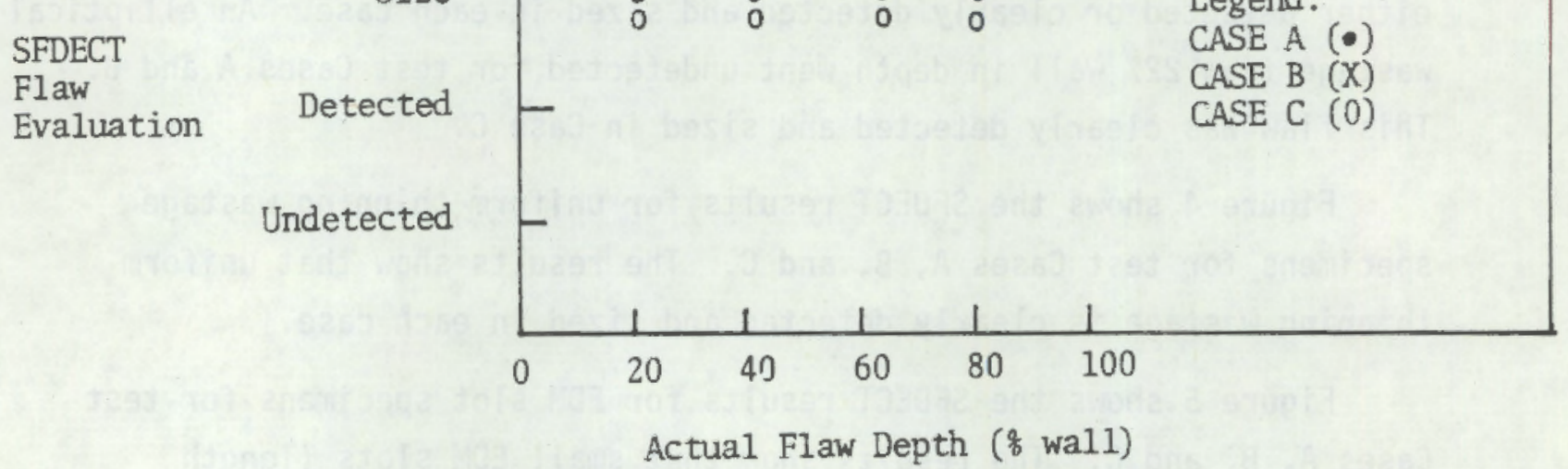

FIGURE 4. Uniform Thinning Wastage Results for SFDECT 
SFDECT

Flaw

Evaluation

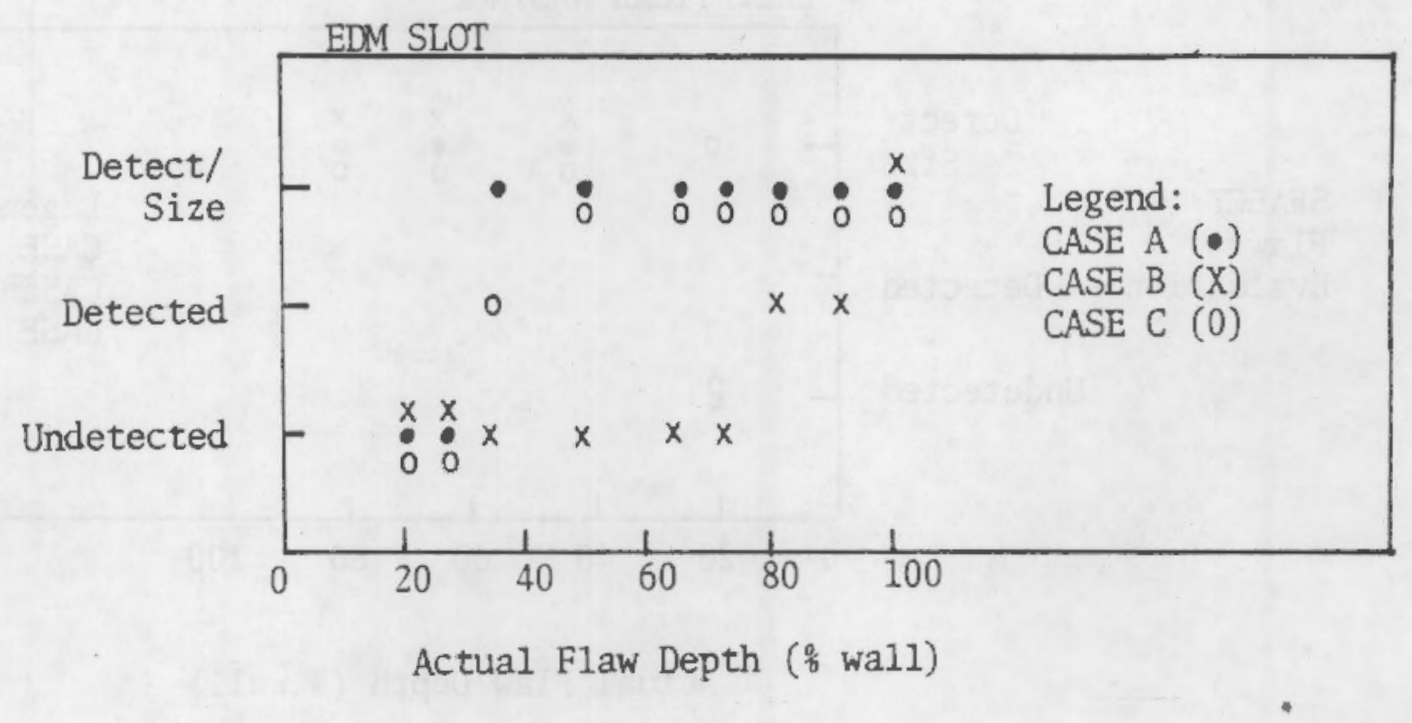

FIGURE 5. EDM S1ot Results for SFDECT 


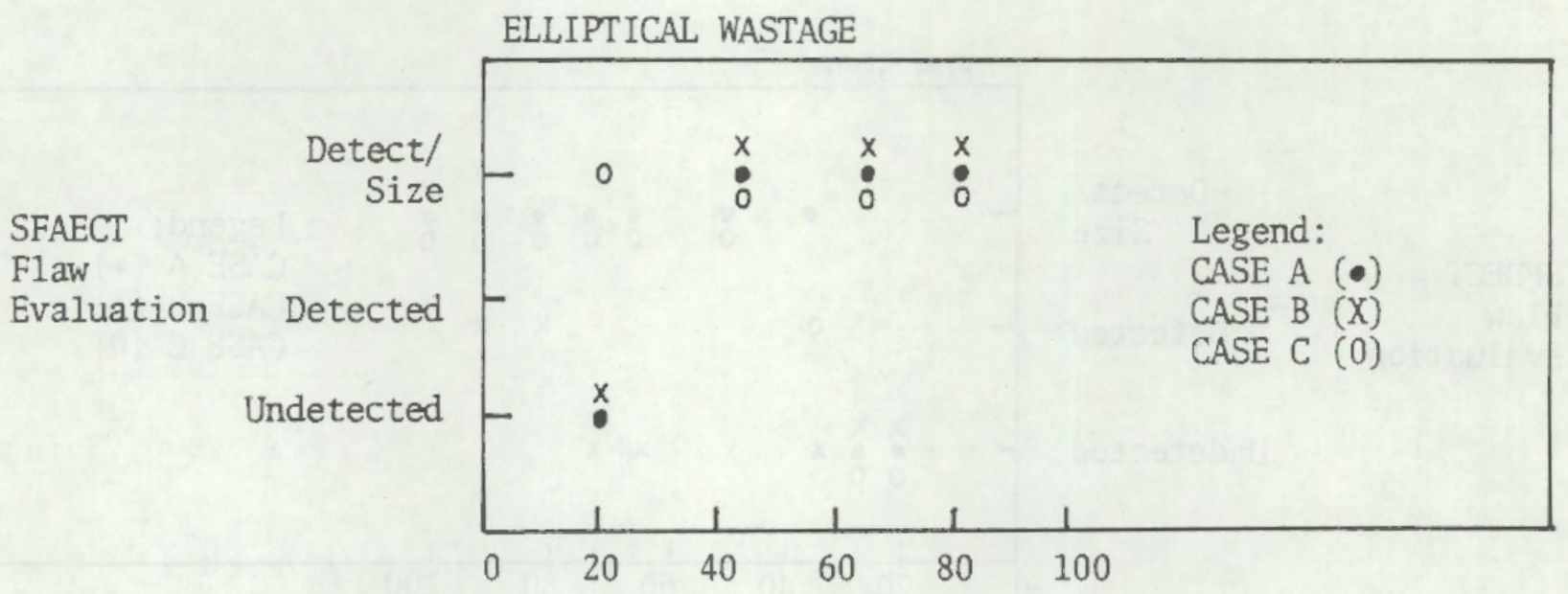

Actual Flaw Depth (\% wall)

FIGURE 6. Elliptical Wastage Results for SFAECT

SFAECT

Flaw

Evaluation

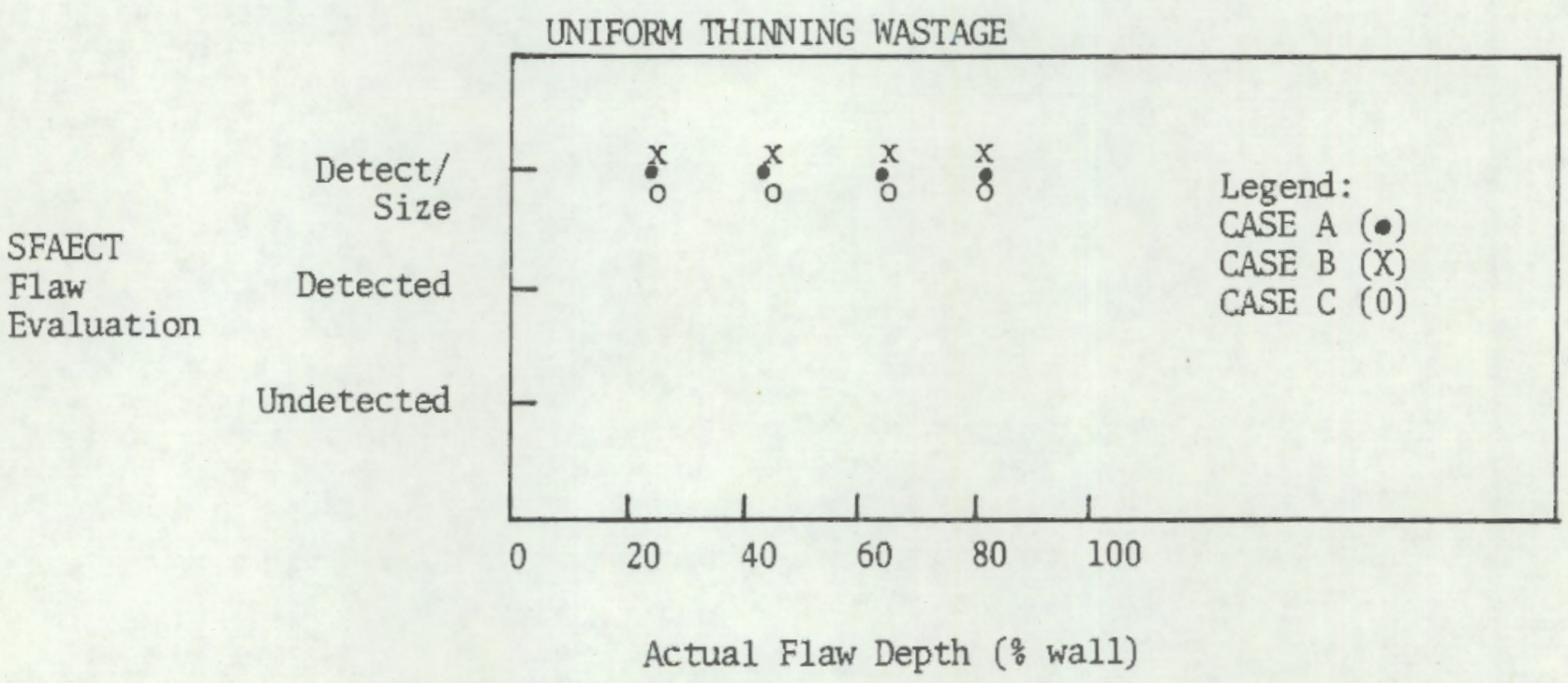

FIGURE 7. Uniform Thinning Wastage Results for SFAECT 
TABLE 4. Single-Frequency Absolute Test Results for a $100 \%$ Stress Corrosion Crack Specimen (B-46-4)

\section{FLAW \\ EVALUATION}

Detected

Detected

Detect/

Size

\section{TEST CASE}

A

B

C
FLAW POSITION
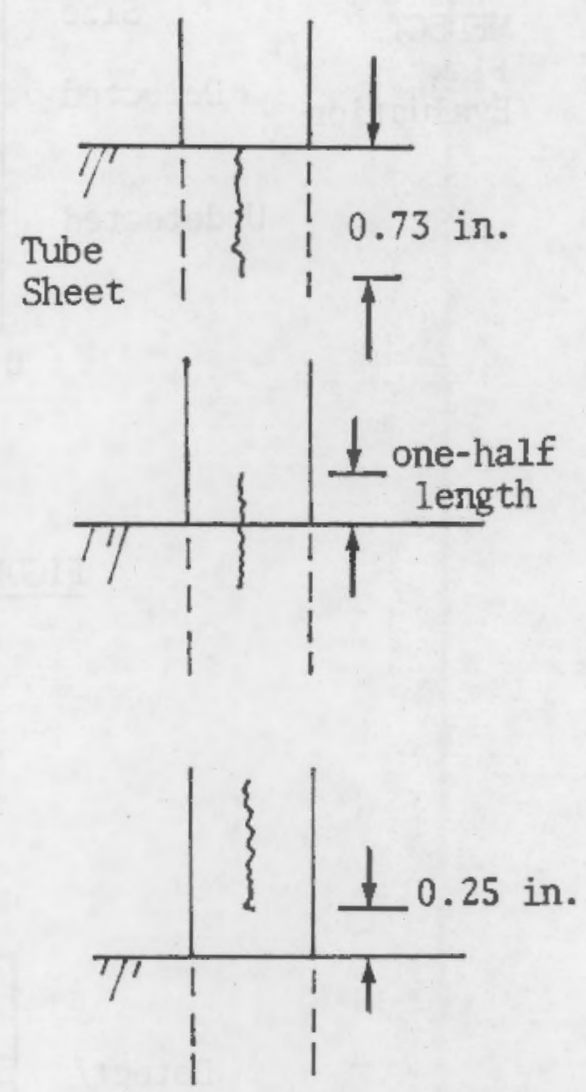


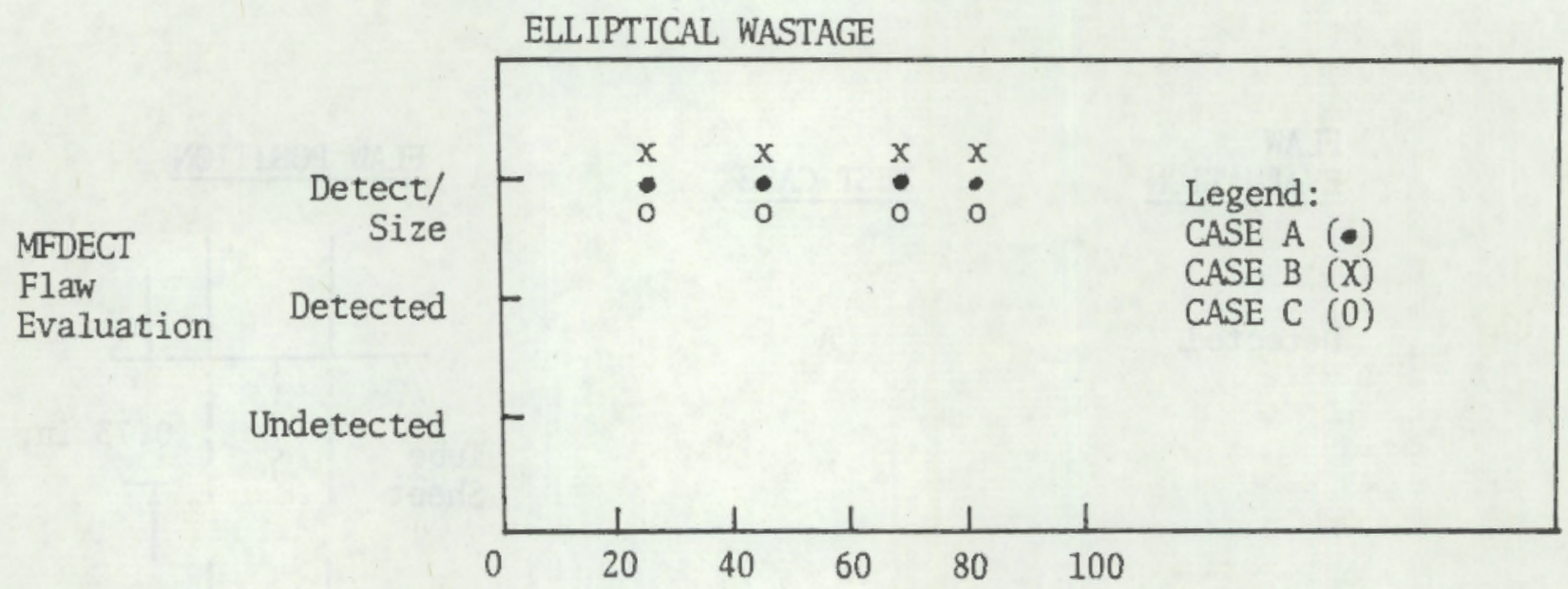

Actual Flaw Depth ( $q$ wall)

FIGURE 8. Elliptical Wastage Results for MFDECT

MFDECT

Flaw

UNIFORM THINNING WASTAGE

Evaluation

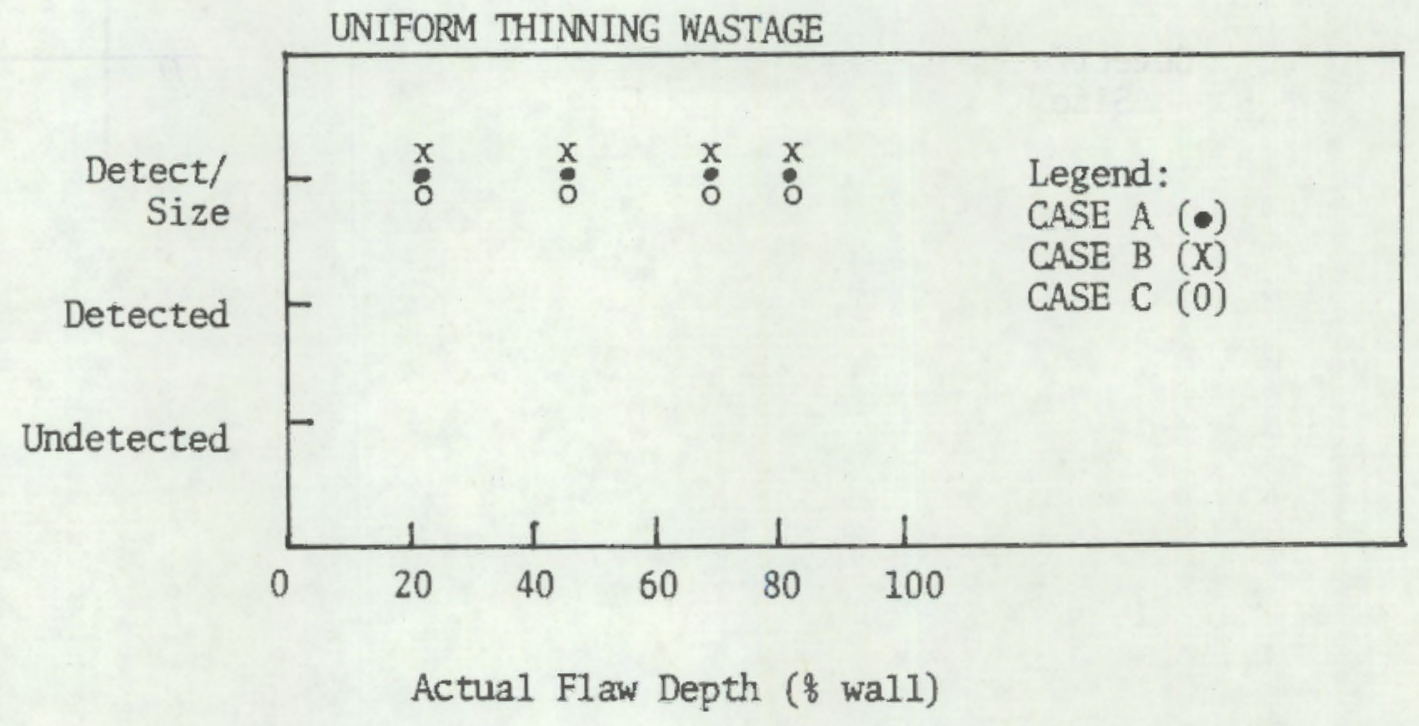

FIGURE 9. Uniform Thinning Wastage Results for MFDECT 
MFDECT

Flaw

Evaluation

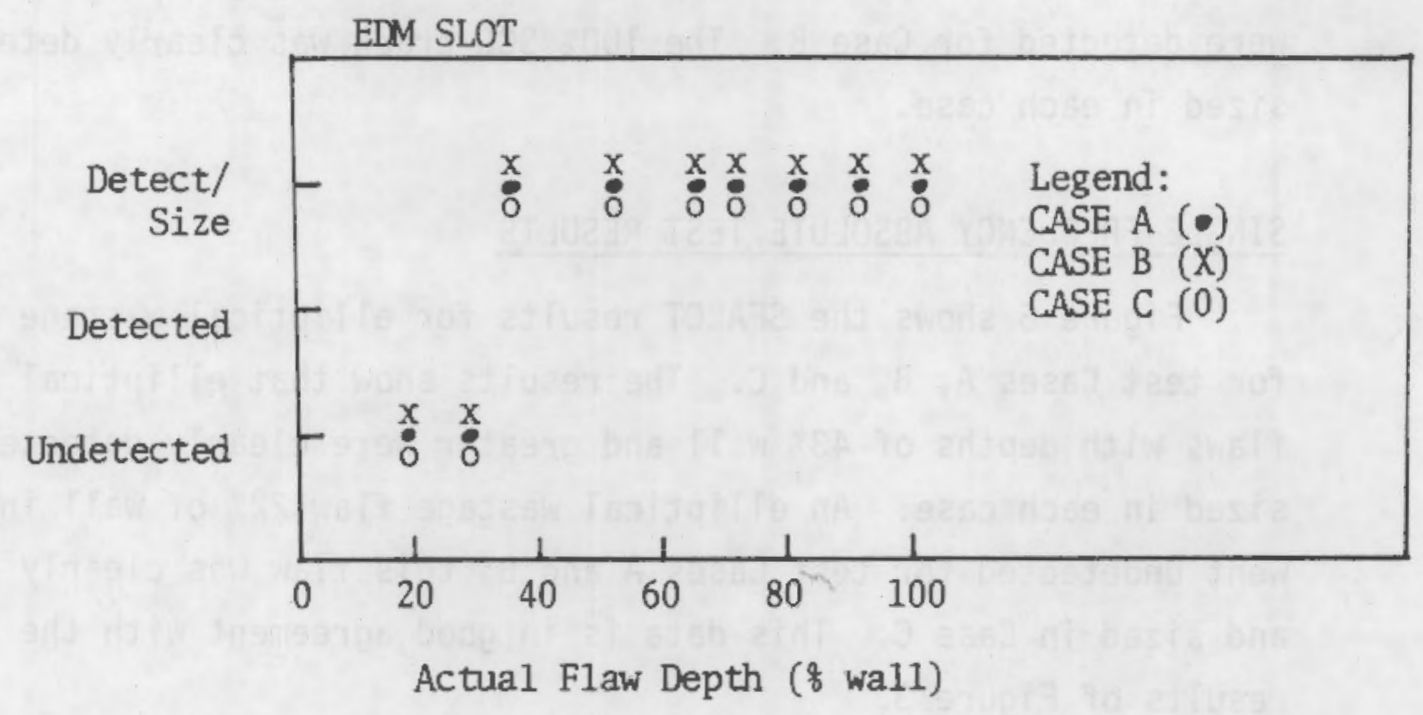

FIGURE 10. EDM Slot Results for MFDECT 
detected and sized in Case $A$, detected in Case $C$, and undetected in Case B. EDM slots that were $50 \%$ of wall and greater in depth were all clearly detected and sized for Case A and Case C. EDM slots $50 \%, 63 \%$, and $71 \%$ of wall were undetected for Case B. S10ts $80 \%$ and $92 \%$ of wa 11 were detected for Case B. The 100\% SCC crack was clearly detected and sized in each case.

\section{SINGLE-FREQUENCY ABSOLUTE TEST RESULTS}

Figure 6 shows the SFAECT results for elliptical wastage specimens for test Cases $A, B$, and $C$. The results show that elliptical wastage flaws with depths of $43 \%$ wall and greater were clearly detected and sized in each case. An elliptical wastage flaw $22 \%$ of wall in depth went undetected for test Cases $A$ and $B$; this flaw was clearly detected and sized in Case $C$. This data is in good agreement with the SFDECT results of Figure 3.

Figure 7 shows the SFAECT results for uniform thinning wastage specimens for test Cases $A, B$, and $C$. The results show that uniform thinning wastage is clearly detected and sized in each case. This data duplicates the uniform thinning results of Figure 4 for SFDECT.

Table 4 shows the results from the examination of a 0.72 inch axial stress corrosion crack specimen that is $80 \%$ at one end and $100 \%$ of wall in depth at the other (viz. depth gradient). This tight crack (width = 0.001 inch) was detected in Cases A and B; it was clearly detected and sized in Case C.

\section{MULTIPLE-FREQUENCY DIFFERENTIAL TEST RESULTS}

Figure 8 shows the MFDECT results for elliptical wastage specimens for test Cases $A, B$, and $C$. The results show that the elliptical wastage flaws were clearly detected and sized in each case.

Figure 9 shows that the uniform thinning wastage was clearly detected and sized in each case.

Figure 10 shows that EDM slots less than $30 \%$ of wall in depth went undetected for each case. EDM slots $36 \%$ of wall and greater were clearly detected and sized in each case. 


\section{CONCLUSION}

The results of this laboratory effort show that multiple-frequency eddy current testing was clearly able to detect and size medium and large volume wastage flaws as small as $20 \%$ of the wall thickness in depth. In addition, the multiple-frequency results show that EDM slots (approximately 0.20 inch long) less than $30 \%$ of the wall thickness in depth went undetected for each test case. Slots greater than $30 \%$ of the wall in depth were clearly detected and sized for each test case.

The single-frequency differential and absolute test results show that elliptical wastage flaws less than $40 \%$ of the wall in depth were undetected in Case A (flaw under tube sheet) and Case B (flaw half under tube sheet). Elliptical wastage flaws $22 \%$ of the wall in depth were clearly detected and sized for Case $C$ (flaw 0.25 inch above tube sheet). Uniform thinning wastage was clearly detected and sized for each test case. Only one SCC sample (approximately 100\% wall) was examined using singlefrequency absolute testing techniques. In Case A (flaw under tube sheet) and Case B (flaw half under tube sheet), our evaluation determined that this flaw was detected, but could not be sized. In Case $C$ (flaw above tube sheet) the SCC crack was clearly detected and sized. On the other hand, the single-frequency differential test results showed that the SCC crack was clearly detected and sized for each case. The singlefrequency differential data for EDM slots showed that slots had to be $80 \%$ of the wall in depth before they could be evaluated as being detected, or clearly detected and sized. Slots positioned half under the tube sheet (Case B) $36 \%$ wall to $71 \%$ wall in depth went undetected. Slots less than $30 \%$ of the wall in depth went undetected, regardless of position.

Many of the SCC samples that were generated during Phase II of the Steam Generator Tube Integrity Program (specifically 30\% to $60 \%$ of wall thickness) were not available for this investigation (sent to Germany). Therefore, it is difficult to assess SCC flaw detectability using single-frequency absolute techniques. The one SCC specimen that was examined would indicate that the absolute technique was less sensitive than the differential technique. 


\section{DISTRIBUTION}

No. of

$\underline{\text { Copies }}$

\section{OFFSITE}

A. A. Churm

DOE Patent Division

$9800 \mathrm{~S}$. Cass Avenue

Argonne, IL 60439

390 U.S. Nuclear Regulatory Commission Division of Technical Information and Document Control

7920 Norfolk Avenue

Bethesda, MD 20014

2 DOE Technical Information Center

10 Dr. Joseph Muscara

Metallurgy and Materials Branch

Reactor Safety Research Division

Nuclear Regulatory Commission

Mail Stop 1130-SS

Washington, D.C. 20555

\section{ONSITE}

38 Pacific Northwest Laboratory

R. A. Clark (25)

T. J. Davis (1)

R. L. Dillon (1)

G. H. Lyon (1)

C. J. Morris (1)

C. B. Perry (1)

G. J. Posakony (1)

Publishing Coordination (2)

Technical Information(5) 


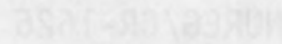

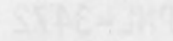

$c^{2}$

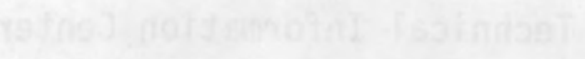


